\title{
Supplementation of Fat Emulsion Improves Fatty Liver due to Total-Parenteral Nutrition in Young Adult Rats
}

\author{
Hiroko Ohkawa ${ }^{12}$, Chie Fukuwa', Naoto MatsuzawaNagata ${ }^{1}$, Koichi Yokogawa ${ }^{12}$, \\ Kenji Omura ${ }^{3}$ and Ken-ichi Miyamoto ${ }^{1,2 *}$ \\ Department of Clinical Pharmacy, Graduate School of Natural Science \\ and Technology, Kanazawa University ${ }^{1}$ \\ Department of Hospital Pharmacy ${ }^{2}$, \\ Department of General and Cardiothoracic Surgery ${ }^{3}$, \\ School of Medicine, Kanazawa University \\ Received November 27, 2007 ]
}

Conscious young adult male rats were given total-parenteral nutrition (TPN) with or without a soybean fat emulsion for 4 days and those that did not receive the emulsion (fat-free TPN group) developed severe fatty liver with hyperglycemia, hyperinsulinemia, and hypotriglyceridemia. These disorders were improved by administering TPN supplemented with soybean fat, equivalent to $20 \%$ of total calories, with glucose correspondingly reduced. In the fat-free TPN group, the expression of sterol regulatory element binding protein 1c (SREBP1C), acetyl-CoA carboxylase (ACC), and fatty acid synthase (FAS) mRNAs in the liver were coordinately up-regulated, resulting in an increase in non-essential fatty acids and a decrease in essential fatty acids in the liver, due to the fat supply drying up. In contrast, expression of carnitine-palmitoyltransferase (CPT) 1a mRNA decreased. However, in the group given the fat emulsion in their TPN, the expressions of all of the above types of mRNA remained similar to those in an oral diet control group.

It appeared that the hyperinsulinemia following infusion of excess glucose had induced lipogenesis and a decrease in fatty acid $\beta$-oxidation in the liver and that these changes were prevented by supplementation of soybean fat equivalent to $20 \%$ of total calories (with a corresponding reduction in glucose). Therefore, it may be appropriate to routinely supplement fat-free TPN with soybean fat in the clinical situation, substituting it for part of the glucose. In addition, serum glucose and insulin levels should be monitored during TPN infusions.

Key words — total-parenteral nutrition, soybean fat emulsion, fatty liver, lipogenesis, fatty acids

\section{Introduction}

Total-parenteral nutrition (TPN) is widely used to provide complete nutritional support to patients who are unable to eat. It is well known that liver dysfunction with steatosis is a common complication after long-term TPN, in both infant and adult patients ${ }^{1-4)}$. In a randomized clinical trial, Buchman et $\mathrm{al}^{5}{ }^{5}$. found that the use of a balanced energy source TPN solution prevents the liver abnormalities, and a TPN solution in which $40 \%$ of total calories were derived from lipid was more effective than one in which $7.5 \%$ of total calories were from lipid. Oshita et $\mathrm{al}^{6}{ }^{6}$. suggested that optimal fat intake may be between $20 \%$ and $40 \%$ of calories in infant rats. Nishimura et $\mathrm{al}^{7}$. reported that metabolic complications in the liver of infant rats owing to excessive administration of fat-free TPN could be prevented by sup- plying $20 \%$ of the total calories from soybean oil. However, in Japan, the clinical situation is still not satisfactory ${ }^{8)}$; in our hospital, only about $30 \%$ of all TPN prescriptions include lipid emulsion supplementation. In the present study we prepared model rats, which continually received drip infusion through the right jugular vein and were able to freely move in metabolic cages. We used these conscious youngadult rats to examine the mechanisms of the hepatic changes arising from fat-free TPN administration, comparing fat-free TPN with TPN in which $20 \%$ of non-protein calories was derived from soybean fat.

\section{Materials and Methods}

\section{Animals and diets}

Male Sprague-Dawley rats at 6 weeks of age were purchased from Nippon SLC Inc. (Hamamatsu, Japan). The rats

\footnotetext{
* 石川市金沢市宝町 13-1；13-1, T akara machi, Kanazawa shi, Ishikawa, 920-8641 Japan
} 
were housed in a light-controlled room (light on from $8: 45$ to $20: 45)$ at a temperature of $25 \pm 2{ }^{\circ} \mathrm{C}$ and humidity of 60 $\pm 10 \%$, and allowed free access to water and a standard diet containing 54.7 starch, 18.8 protein, 3.9 fat, 6.6 fiber, and 6.9 mineral and vitamin mixture (LABO MR STOCK ${ }^{\circledR}$, Nosan Co., Y okohama, Japan) for one week. All animal procedures were in accordance with the standards set forth in the Guidelines for the Care and Use of Laboratory Animals at the Takara machi campus of Kanazawa University, Japan.

\section{Surgery and TPN solution preparation}

Rats were divided into three groups (five in each group). Each rat in the sham-operated control group received a standard oral diet (total energy $259.2 \mathrm{kcal} / 100 \mathrm{~g}$ ) and tap water freely in a stainless steel wired metabolic cage. In the TPN groups, the rats were fasted overnight, then a polyethylene catheter (I.D.0.58 mm, O.D.0.96 mm) for the infusion of parenteral nutrition was placed, under anesthesia with pentobarbital sodium (50 mg/ kg, intraperitoneally), in the right jugular vein into the superior vena cava and routed to the back of the neck to exit through a coil spring attached to a swivel. When the rats recovered consciousness, they were housed in stainless steel wire metabolic cages, in which tap water was freely available. The TPN groups continuously received an increasing amount in a stepwise manner using an infusion pump (BRIFSYS-R 1, Bioresearch Center Co., Tokyo, Japan) $: 5 \mathrm{~mL} / \mathrm{kg}$ body weight $/ \mathrm{h}(120 \mathrm{kcal} / \mathrm{kg} /$ day $)$ from just after cannulation for the first $24 \mathrm{~h}$, then $10 \mathrm{~mL} /$ $\mathrm{kg} / \mathrm{h}(240 \mathrm{kcal} / \mathrm{kg} /$ day $)$ for the next $24 \mathrm{~h}$ ( $2^{\text {nd }}$ day $)$, and 15 $\mathrm{mL} / \mathrm{kg} / \mathrm{h}$ ( $360 \mathrm{kcal} / \mathrm{kg} /$ day) for the $3 \mathrm{rd}$ to 4 th day. The compositions of the TPN solutions are shown in Table 1. The fat-free TPN group received only the basal TPN solution (A miparen ${ }^{\circledR}$, Otsuka Pharmaceutical Co. Ltd., Tokyo, Japan) and the TPN with fat group received basal solution supplemented with soybean fat equivalent to $20 \%$ of total calories (Intralipos ${ }^{\circledR}$, Otsuka Pharmaceutical), with a corresponding decrease of glucose concentration. Vitamedin IV ${ }^{\circledR}$ (Daiichi-Sankyo Co. Ltd., Tokyo, Japan) was used to supply vitamins.

Table 1. Formulation of TPN solutions.

\begin{tabular}{lcc}
\hline & Fat-free TPN & TPN with fat \\
\hline Glucose $(\mathrm{g})$ & 182 & 140 \\
Fat $(\mathrm{g})$ & 0 & 18 \\
Amino acids $(\mathrm{g})$ & 36 & 36 \\
$\mathrm{Na}(\mathrm{mEq})$ & 35 & 35 \\
$\mathrm{~K}(\mathrm{mEq})$ & 27 & 27 \\
$\mathrm{Mg}(\mathrm{mEq})$ & 5 & 5 \\
$\mathrm{Ca}(\mathrm{mEq})$ & 7.8 & 7.8 \\
$\mathrm{Cl}(\mathrm{mEq})$ & 54 & 54 \\
$\mathrm{P}(\mathrm{mmol})$ & 6.5 & 7.8 \\
Zn $(\mu \mathrm{mol})$ & 20 & 20 \\
\hline
\end{tabular}

TPN calories per unit volume : $880 \mathrm{kcal} / 880 \mathrm{~mL}$.

Caloric ratio of carbohydrate calories to nitorogen : 130 .

Added fat emultion is consist of $55 \%$ linoleic acid(18:2), $25 \%$ oleic $\operatorname{acid}(18: 1), 8 \%$ palmitic $\operatorname{acid}(16: 0), 8 \%$ a-linolenic $\operatorname{acid}(18: 3)$, and $3 \%$ stearic $\operatorname{acid}(18: 0)$.

\section{Biochemical and pathological examinations}

Blood samples were collected from the left jugular vein, and centrifuged to provide serum samples, which were stored at $-80^{\circ} \mathrm{C}$ until assay. The animals were killed imme diately after blood sampling under deep diethyl ether anes thesia. After weighing liver, a part of liver specimen was fixed in $10 \%$ buffered formalin and stained with Oil red 0 and hematoxylin-eosin according to the standard methods, and other parts were used for biochemical examinations.

A spartate aminotransferase (AST), alanine aminotransferase $(A L T)$, alkaline phosphatase $(A L P), Y$-glutamyl transpeptidase $(Y-G T P)$, phospholipids $(P L)$ and fatty acids were measured by SRL Co., Ltd. (Tokyo, Japan). Triglyceride (TG), total cholesterol (TC), free fatty acid (FFA), glucose, and insulin were measured in our laboratory using commercially available assay kits (Wako Pure Chemical, Co., Osaka, Japan).

Hepatic lipids were extracted with chloroform : methanol (2: 1), according to a published method ${ }^{9}$. The extract was dissolved in water and subsequently analyzed for TG, TC, and FFA using respective kits (Wako).

\section{Reverse transcriptase-polymerase chain reaction (RT- PCR) assay}

Total RNA was isolated from the liver by using an Isogen Kit (Nippon Gene, Tokyo, Japan). Synthesis of cDNA from the isolated total RNA was carried out using RNase $\mathrm{H}$ - re verse transcriptase (GIBCO BRL, Rockville, MD). Reverse transcription (RT) reactions were carried out in $40 \mathrm{mM} \mathrm{KCl}$, $50 \mathrm{mM}$ Tris $\mathrm{HCl}$ ( $\mathrm{pH}$ 8.3), $6 \mathrm{mM} \mathrm{MgCl}_{2}, 1 \mathrm{mM}$ dithiothreitol, $1 \mathrm{mM}$ each of dATP, dCTP, dGTP, and dTTP, 10 units of RNase inhibitor (Promega, Madison, WI), $100 \mathrm{pmol}$ of random hexamer, total RNA and 200 units of the Moloney murine leukemia virus reverse transcriptase (Gibco-BRL, Berlin, Germany) in a final volume of $5 q \mathrm{~L}$ at $37^{\circ} \mathrm{C}$ for 60 min. Polymerase chain reaction (PCR) was carried out in a final volume of $2 q u L$, containing $1 \mu L$ of $R T$ reaction mixture, $50 \mathrm{mM} \mathrm{KCl}, 20 \mathrm{mM}$ Tris $\mathrm{HCl}$ (pH 8.3), $2.5 \mathrm{mM}$ $\mathrm{MgCl}_{2}, 0.2 \mathrm{mM}$ each of dATP, dCTP, dGTP, and dTTP, 10 $\mu \mathrm{M}$ each of the mixed oligonucleotide primers, and 1 unit of Taq DNA polymerase (Gibco-BRL). Primers used for rat SREBP-1 $c^{10)}$ were 5'-GGA GCC ATG GAT TGC ACA TT3' and 5'-AGG AAG GCT TCC AGA GAG GA-3' (191 bp), those for rat $A C C 1^{11}$ ) were 5'-CAG ACA GGT TCA AGC TGA AGT CCC T-3' and 5'-GCT GTG CTG CAG GAA GAT TGA CAT C-3' (383bp), those for rat $F A S^{12)}$ were 5'-TGC AAC TGT GCG TTA GCC ACC-3' and 5'TGT TTC AGG GGA GAA GAG ACC-3' (710 bp), those for rat $C P T 1 a^{13)}$ were 5'-AGT GAG GAC CAT AAG CAG AG-3' and 5'-ACG TCT GGA CCT AAA GCA GAG-3' (590 bp), and those for rat $\beta$-actin were 5'-TTC TAC AAT GAG CTG CGT GTG GC-3' and 5'-CTC (A/G)TA GCT CTT CTC CAG GGA GGA-3' (456 bp), as previously re ported by Waki et $\mathrm{al}^{14)}$. Each cycle consisted of $60 \mathrm{sec}$ at 95 ${ }^{\circ} \mathrm{C}, 60 \mathrm{sec}$ at $62^{\circ} \mathrm{C}$, and $60 \mathrm{sec}$ at $72^{\circ} \mathrm{C}$ for SREBP-1 c, 60 $\sec$ at $95^{\circ} \mathrm{C}, 60 \mathrm{sec}$ at $65^{\circ} \mathrm{C}$, and $60 \mathrm{sec}$ at $72^{\circ} \mathrm{C}$ for $A C C 1$, 
$60 \mathrm{sec}$ at $95^{\circ} \mathrm{C}, 60 \mathrm{sec}$ at $62^{\circ} \mathrm{C}$, and $60 \mathrm{sec}$ at $72^{\circ} \mathrm{C}$ for $F A S$, $60 \mathrm{sec}$ at $95^{\circ} \mathrm{C}, 60 \mathrm{sec}$ at $55^{\circ} \mathrm{C}$, and $60 \mathrm{sec}$ at $72^{\circ} \mathrm{C}$ for $C P T$ $1 \mathrm{a}$, and $60 \mathrm{sec}$ at $95^{\circ} \mathrm{C}, 60 \mathrm{sec}$ at $62^{\circ} \mathrm{C}$, and $60 \mathrm{sec}$ at $72^{\circ} \mathrm{C}$ for $\beta$-actin. PCR reaction was run for 26 cycles for $S R E B P$ $1 c$, ACC 1 , and FAS, and for 22 cycles for $\beta$-actin, respectively.

\section{Data analysis}

Student's t-test was used to compare the unpaired mean values of two sets of data. Regression analysis was performed using Pearson's correlation coefficient test. $P$ values less than 0.05 were considered statistically significant.

\section{Results}

\section{Pathologic observations of the liver}

When young-adult rats were received TPN with or without fat for 4 days, the body weight was not different among three groups, but the liver weight of the group given fat-free TPN was enlarged to double as compared with that of the oral diet control group (Table 2). The liver weight of the TPN with fat group was intermediate between those of the control group and the fat-free TPN group. In pathological finding, severe steatosis was observed in the liver of rats re ceived fat-free TPN, whereas fat supplementation improved the hepatic lipid accumulation (Fig. 1).

\section{Biochemical findings}

Fig. 2 shows the lipid levels in the liver. The contents of TG and TC were significantly increased in rats given fat-free
TPN and were moderately increased in the TPN with fat group. In contrast, the content of PL was decreased in the fat-free TPN group.

A mong hepatic biomarkers, serum AST and ALT were significantly increased after fat-free TPN and were improved by fat supplementation (T able 2). Blood glucose and insulin levels were also significantly increased by fat-free TPN. Fatfree TPN significantly decreased the serum concentrations of TG, TC, and FFA, and fat supplemention in the TPN almost completely blocked the decrease in the lipid concentrations, except for TG (Table 2). Other laboratory data were hardly influenced by TPN with or without fat.

\section{3. mRNA expression}

The changes of expression of lipid metabolism-related mRNA s in the liver after TPN infusion were examined using semi-quantitative RT-PCR (Fig. 3). The expression of mRNAs of a transcriptional regulator of fatty acid synthesis, sterol regulatory element binding protein $1 c(\mathrm{SREBP} 1 \mathrm{c})^{15)}$, and lipogenic enzymes, acetyl-CoA carboxylase 1 (ACC1) and fatty acid synthase (FAS) was significantly up-regulated after fat-free TPN infusion. In contrast, the mRNA expression of carnitine palmitoyltransferase $1 \mathrm{a}$ (CPT-1a), which is the rate-limiting enzyme of $\beta$-oxidation in liver mitochondria ${ }^{16)}$ was down-regulated by fat-free TPN. However, fat supple mentation completely suppressed these changes.

\section{Fatty acid composition in the liver}

As shown in Table 3 , in rats that had received fat-free TPN for 4 days, the hepatic contents of non-essential fatty

Table 2. Body and liver weight and biochemical data

\begin{tabular}{|c|c|c|c|}
\hline & Control & Fat-free TPN & TPN with fat \\
\hline Body weight $(\mathrm{g})$ & $200 \pm 7$ & $194 \pm 6$ & $195 \pm 5$ \\
\hline Liver weight $(\mathrm{g})$ & $8.0 \pm 0.9$ & $16.7 \pm 1.8^{* *}$ & $12.2 \pm 1.0^{* *}, \# \#$ \\
\hline $\begin{array}{c}\text { Liver weight ratio } \\
(\mathrm{g} / 100 \text { g body weight) }\end{array}$ & $3.8 \pm 0.4$ & $8.6 \pm 0.8^{* *}$ & $6.3 \pm 0.5^{* *}, \# \#$ \\
\hline Serum & & & \\
\hline AST (IU/L) & $89 \pm 6$ & $204 \pm 67^{*}$ & $98 \pm 7 \#$ \\
\hline ALT $(\mathrm{IU} / \mathrm{L})$ & $53 \pm 5$ & $96 \pm 21^{*}$ & $39 \pm 14 \# \#$ \\
\hline ALP $(\mathrm{IU} / \mathrm{L})$ & $1122 \pm 223$ & $1274 \pm 241$ & $1175 \pm 220$ \\
\hline$\gamma-\mathrm{GTP}(\mathrm{IU} / \mathrm{L})$ & $<2$ & $4 \pm 2$ & $3 \pm 1$ \\
\hline Glucose $(\mathrm{mg} / \mathrm{dL})$ & $117 \pm 4$ & $304 \pm 83^{* *}$ & $147 \pm 57 \ldots$ \\
\hline Insulin $(\mu \mathrm{IU} / \mathrm{mL})$ & $73 \pm 21$ & $248 \pm 16^{* *}$ & $142 \pm 14^{*}, \# \#$ \\
\hline TG $(\mathrm{mg} / \mathrm{dL})$ & $60 \pm 9$ & $7.7 \pm 2.0^{* *}$ & $21 \pm 5^{* *}, \# \#$ \\
\hline TC $(\mathrm{mg} / \mathrm{dL})$ & $87 \pm 15$ & $36 \pm 13^{* *}$ & $74 \pm 10 \# \#$ \\
\hline FFA $(\mu \mathrm{Eq} / \mathrm{L})$ & $294 \pm 110$ & $130 \pm 42^{* *}$ & $246 \pm 56 \# \#$ \\
\hline PL $(\mathrm{mg} / \mathrm{dL})$ & $111 \pm 7$ & $107 \pm 24$ & $113 \pm 20$ \\
\hline
\end{tabular}

Data are represented the meanst S.D. of 5 rats.

* , * * Significantly different from the oral diet control group at $P<0.05$ and 0.01 , respectively.

\# , \# \# Significantly different from the fat-free TPN group at $P<0.05$ and 0.01 , respectively. 


\section{a) Control}

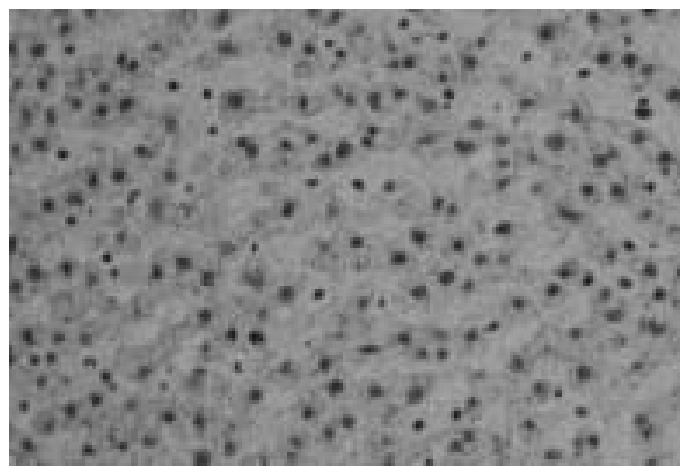

b) Fat free

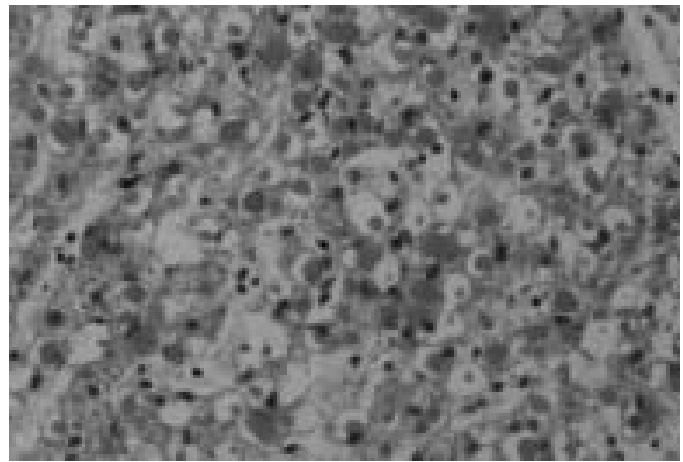

c) With fat

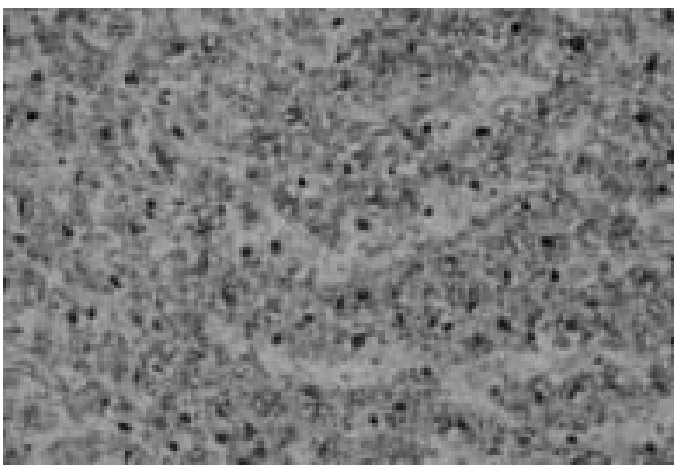

Fig 1. Light micrographs of the liver after 4 days administration (Hematoxylin and Oil red $O$ double stain. The original magnification was X 200).

a) TG

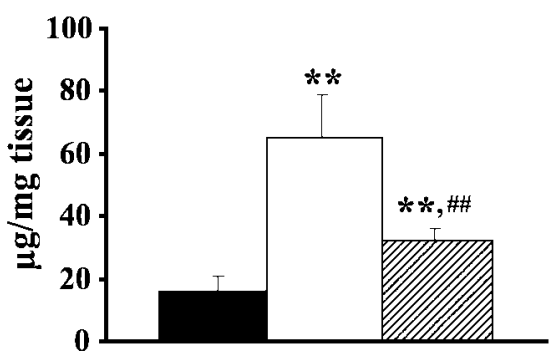

c) FFA

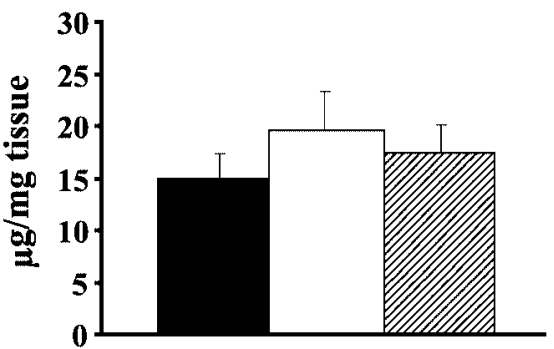

b) $\mathrm{TC}$

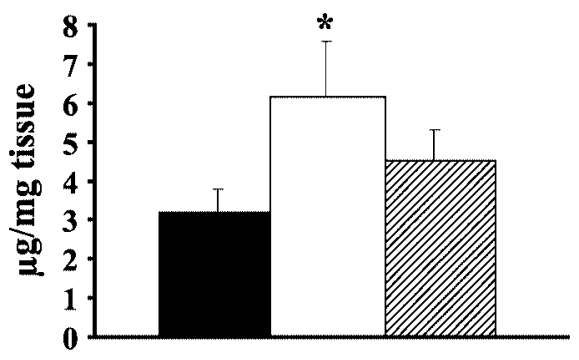

d) PL

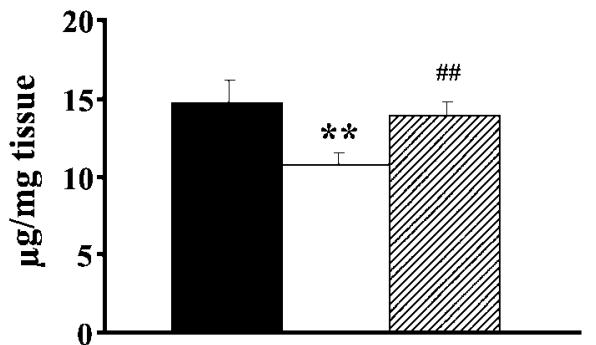

Fig 2. Hepatic lipid contents after oral diet ( $\square$ ), fat-free TPN ( $\square$ ) and TPN with fat (

Data are presented the means \pm S.D. of 5 rats.

* , * * Significantly different from the oral diet control group at $P<0.05$ and 0.01 , respectively.

\# " Significantly different from the fat-free TPN group at $P<0.01$. 

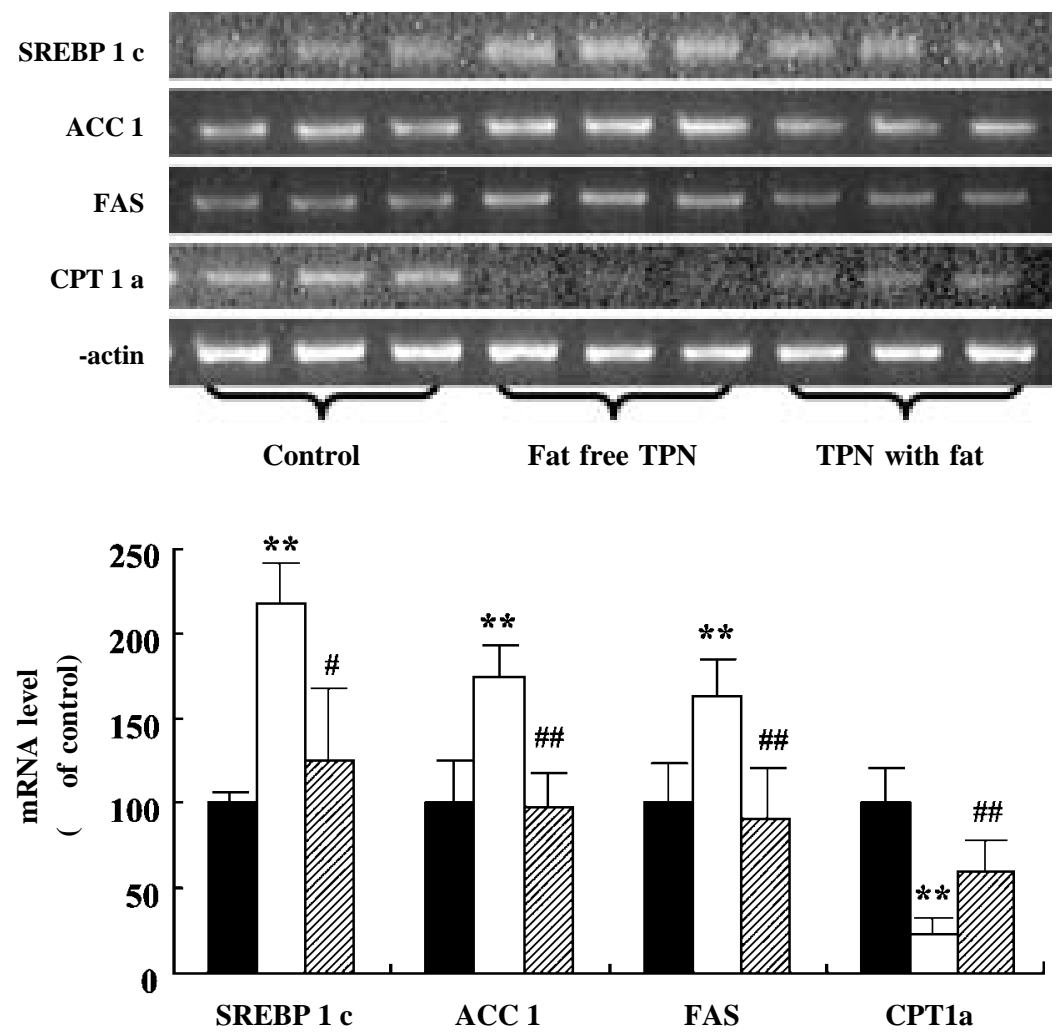

Fig 3. Expression lipid metaboliism-related mRNAs after oral

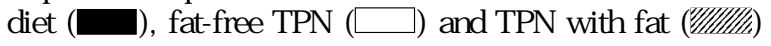
for 4 days.

Data are presented the meanst S.D. of 5 rats.

${ }^{*}$ * Significantly different from the oral diet control group at $P<0.01$.

\# , \# \# Significantly different from the fat-free TPN group at $P<0.05$ and 0.01 , respectively.

acids, palmitic acid, palmitoleic acid, oleic acid, and eicosa trienoic acid were significantly increased, while the concentrations of essential fatty acids, including linoleic acid and arachidonic acid, were decreased compared with those of the oral diet control group, as reported in deficiency of essential fatty acids $^{17}$. Although the supplemented fat contains high levels of linoleic acid and oleic acid, the composition of these fatty acids in the liver was increased only slightly, but with statistical significance, and the supplemented fat appeared mainly to inhibit the changes of fatty acid composition resulting from fat-free TPN administration. The supplementation of TPN with fat completely blocked the decrease in essential fatty acids caused by fat-free TPN.

Recent studies have shown that long-chain polyunsaturated fatty acid (LCPUFA), which is produced through the pathways for desaturation and elongation of the essential fatty acids linoleic acid and $a$-linolenic acid, (i) inhibits the transcription of lipogenic genes, such as SREBP- $1 c^{18)}$, and that (ii) activates peroxisome proliferator-activated receptor a (PPARa), a key up-regulator of peroxisomal and mitochondrial fatty acid $\beta$-oxidation, leading to improvement of fat accumulation ${ }^{19}{ }^{20}$. Both n-6 and n-3 LCPUFAs were de creased in the liver of rats received fat-free TPN, whereas fat supplementation fully recovered hepatic contents of LCPUFAs (Table 3). These results are consist with the observation that fat-free TPN up-regulated genes for lipogenic enzymes and down-regulated CPT-1a mRNA.

\section{Discussion}

Our results confirmed that fat-free TPN caused severe fatty liver with hyperglycemia, hyperinsulinemia, and hypolipidemia in conscious young-adult rats after infusion for only 4 days, whereas these disorders were much less severe in rats given TPN supplemented with soybean fat emulsion equivalent to $20 \%$ of total calories. Administration of TPN with fat also ameliorated the increase in hepatic biomarkers (Fig. 2, Table 2). We suggest that the biochemical mecha nisms leading to lipid accumulation in the liver after fat-free TPN are as follows: the infusion of excess glucose causes hyperinsulinemia, and the insulin increases lipogenesis and decreases $\beta$-oxidation, resulting in high synthesis and accu- 
Table 3 . Fatty acids composition of the liver

\begin{tabular}{|c|c|c|c|c|}
\hline & & Control & Without fat & With fat \\
\hline Palmitic acid & $16: 0$ & $4.65 \pm 0.21$ & $27.4 \pm 6.1 * *$ & $14.4 \pm 2.0^{* *}, \#$ \\
\hline Palmitoleic acid & $16: 1, \mathrm{n}-7$ & $0.23 \pm 0.10$ & $11.4 \pm 3.5 *$ & $2.53 \pm 0.94^{*}, \#$ \\
\hline Stearic acid & $18: 0$ & $5.19 \pm 0.35$ & $4.87 \pm 0.12$ & $5.19 \pm 0.06 \#$ \\
\hline Oleic acid & $18: 1, \mathrm{n}-9$ & $1.18 \pm 0.33$ & $15.7 \pm 2.1^{* *}$ & $7.01 \pm 1.38^{* *}$ \\
\hline Linoleic acid & $18: 2, \mathrm{n}-6$ & $4.06 \pm 0.35$ & $0.50 \pm 0.03^{* *}$ & $5.22 \pm 0.42 *$,\#\# \\
\hline$\alpha$-Linolenic acid & $18: 3, \mathrm{n}-3$ & $0.03 \pm 0.01$ & $0.00 \pm 0.00 * *$ & $0.23 \pm 0.08^{*}$ \\
\hline$\gamma$-Linolenic acid & $18: 3, \mathrm{n}-6$ & $0.04 \pm 0.00$ & $0.04 \pm 0.00$ & $0.09 \pm 0.01 *$ \\
\hline 5-8-11 Eicosatrienoic acid & $20: 3, n-9$ & $0.03 \pm 0.01$ & $0.25 \pm 0.04 * *$ & $0.04 \pm 0.01 \ldots$ \\
\hline Arachidonic acid & $20: 4, n-6$ & $3.13 \pm 0.36$ & $1.45 \pm 0.07^{*}$ & $3.08 \pm 0.20 \# \#$ \\
\hline Eicosapentaenoic acid & $20: 5, n-3$ & $0.13 \pm 0.01$ & $0.08 \pm 0.00 * *$ & $0.11 \pm 0.03$ \\
\hline Docosahexaenoic acid & $22: 6, n-3$ & $1.27 \pm 0.14$ & $0.71 \pm 0.04 * *$ & $1.08 \pm 0.09$ \#\# \\
\hline Total LCPUFA & & $4.58 \pm 0.49$ & $3.35 \pm 0.07 * *$ & $4.32 \pm 0.29 \#$ \\
\hline Total n-6 LCPUFA & & $3.13 \pm 0.36$ & $1.50 \pm 0.07 * *$ & $3.08 \pm 0.20 \# \#$ \\
\hline Total n-3 LCPUFA & & $1.39 \pm 0.13$ & $0.80 \pm 0.04 * *$ & $1.20 \pm 0.10 \# \#$ \\
\hline
\end{tabular}

Data are represented the means \pm S.D. of 5 rats. $\mathrm{n}-6$ LCPUFA is $20: 4, \mathrm{n}-6$; $\mathrm{n}-3$ LCPUFA are $20: 5, \mathrm{n}-3$ and $22: 6, \mathrm{n}-3$.

* ${ }^{*}{ }^{*}$ Significantly different from the oral diet control group at $P<0.05$ and 0.01 , respectively.

\# , \# \# Significantly different from the fat-free TPN group at $P<0.05$ and 0.01 , respectively.

mulation of TG in the liver. It has been known that insulin promotes the gene expression of lipid synthesis related enzymes, such as ACC and FAS, through activation of transcription factors SREBPs ${ }^{21}$. SRBP1c is essential for induction of ACC and FAS, but not other lipogenic enzymes, glucose 6-phosphatase dehydrogenase, glycerol-3-phosphate acyltransferase, etc. This study indicated significant increase in the expression of SREBP1C, ACC, and FAS (Fig. 3), resulting increase in the contents of non-essential fatty acids, such as palmitic acid, palmitoleic acid, stearic acid and oleic acid, in the liver of rats given fat-free TPN (T able 3). In addition, the decreased essential fatty acids in the liver caused by depletion of fat component in TPN seems to impair LCPUFA production, resulting in liver steatosis. These changes were improved by TPN with soybean fat equivalent to $20 \%$ of total calories, with a corresponding reduction of glucose (the formulation is shown in Table 1).

A mong lipids in the liver, only PL was decreased by administration of fat-free TPN (Fig. 2). Large amounts of PL and lecithin are synthesized using plant choline, and fat-free TPN has been reported to induce choline deficiency and to decrease $\mathrm{PL}^{22}{ }^{23}$. Because the soybean fat emulsion (Intralipos ${ }^{\circledR}$ ) used in this study contains egg-lecithin as an emulsifier, it seems that the PL content and choline deficiency were improved by administration of TPN supplemented with fat, compared with fat-free TPN.

CPT 1 is located at the outer membrane of mitochondria and is the rate-limiting enzyme in the $\beta$-oxidation of longchain fatty acids. CPT1 $\mathrm{a}$ is the liver-type isoform of CPT 16). In this study, the expression of mRNA of CPT1a was found to be significantly decreased after fat-free TPN, but not TPN with fat (Fig. 3), although it is not yet clear whether the expression of CPT is regulated by insulin and glucose. Consequently, administration of fat-free TPN not only increased lipogenesis as a result of hyperglycemia and hyperinsulinemia, but also decreased $\beta$-oxidation, resulting fatty liver. Moreover, ACC stimulated by insulin has been reported to suppress the CPT-1 activity through increased synthesis of malonyl- $\mathrm{CoA}^{24}$. These results and evidence indicated that hyperinsulinemia lowered the ability of CPT to transport fatty acid into mitochondria and decreased $\beta$ oxidation. On the other hand, while lipid was accumulated in the liver after fat-free TPN, serum lipids were significantly lowered (Table 2). The low serum lipid concentration was not seen when TPN supplemented with soybean fat was used. Lipids synthesized in the liver assemble with apo B through the action of microsomal triglyceride transfer protein (MTP) and are secreted as very low density lipoprotein (VLDL) into the bloodstream ${ }^{25}$. It has been reported that acute hyperinsulinemia suppresses the hepatic secretion of $V L D L^{12,13)}$. Thus, the low serum lipid concentration might have been caused by hyperinsulinemia after fat-free TPN, and supplementation of TPN with fat in place of a part of the glucose may improve insulin secretion and lipid metabolism. However, it remains to examine the correlation among activities of MTP, VLDL-degradation protein, and lipoprotein lipase, and the infusion of TPN with or without fat.

In conclusion, we found that fat-free TPN caused severe fatty liver with hyperglycemia, hyperinsulinemia, and hypolipidemia after administration for only 4 days, and these dis orders were clearly less severe when TPN supplemented with soybean lipid, equivalent to $20 \%$ of total calories, was 
used. Therefore, we should avoid the use of fat-free TPN in the clinical context. Instead, TPN should be routinely supplemented with soybean fat at an appropriate level in place of a part of the glucose. It may also be necessary to monitor serum glucose and insulin concentrations during TPN infusion.

\section{References}

1) A.L. Baker, I.H. Rosenberg, Hepatic complications of total parenteral nutrition, Am. J. Med., 82, 489-497 (1987).

2) D.R. Benjamin, Hepatobiliary dysfunction in infants and children associated with long-term total parenteral nutrition. A clinico-pathologic study, Am. J. Clin. Pathol ., 76, 276-283 (1981).

3) Y.A. Carpentier, M. Van Brandt, Effect of total parenteral nutrition on liver function, Acta. Chir. Belg., 80, 141-144 (1981).

4) K.D. Lindor, C.R. Fleming, A. A brams, M.A. Hirschkorn, Liver function values in adults receiving total parenteral nutrition. JAMA., 241, 2398-2400 (1979).

5) A.L. Buchman, M.E. A ment, M. Sohel, M. Dubin, D.J. Jenden, M. Roch, H. Pownall, W. Farley, M. Awal, C. A hn, Choline deficiency causes reversible hepatic abnormalities in patients receiving parenteral nutrition: proof of a human choline requirement: a placebocontrolled trial, J. Parenter. Enteral. Nutr., 25, 260268 (2001).

6) M. Oshita, H. Takehara, M. Yamaguchi, K. Doi, N. Ueda, S. Naito, I. Hiraoka, S. Tashiro, Significance of administration of fat emulsion: hepatic changes in infant rats receiving total parenteral nutrition with and without fat, Clin. Nutr., 23, 1060-1068 (2004).

7) M. Nishimura, M. Y amaguchi, S. Naito, A. Y amauchi, Soybean oil fat emulsion to prevent TPN-induced liver damage: possible molecular mechanisms and clinical implications, Biol. Pharm. Bull ., 29, 855-862 (2006).

8) K. Iriyama, Inclusion of fat emulsion in regimens for parenteral nutrition: Current situation and future perspectives in japan, The Journal of Japanese Society for Parenteral and Enteral Nutrition, 19, 82-85 (2004).

9) J. Folch, M. Lees, G.H. Sloane Stanley, A simple method for the isolation and purification of total lipides from animal tissues, J. Biol. Chem., 226, 497-509 (1957).

10) T. Kakuma, Y. Lee, M. Higa, Z. Wang, W. Pan, I. Shimomura, R.H. Unger, Leptin, troglitazone, and the expression of sterol regulatory element binding proteins in liver and pancreatic islets, Proc. Natl. Acad. Sci. U. S. A., 97, 8536-8541 (2000).

11) A.K. Stoeckman, H.C. Towle, The role of SREBP-1c in nutritional regulation of lipogenic enzyme gene expression, J. Biol. Chem., 277, 27029-27035 (2002).

12) G.F. Lewis, G. Steiner, Acute effects of insulin in the control of VLDL production in humans. Implications for the insulin-resistant state, Diabetes Care, 19, 390393 (1996).

13) G.F. Lewis, K.D. Uffelman, L.W. Szeto, B. Weller, G. Steiner, Interaction between free fatty acids and insulin in the acute control of very low density lipoprotein production in humans, J. Clin. Invest., 95, 158-166 (1995).

14) Y. Waki, K. Miyamoto, S. Kasugai, K. Ohya, Osteoporosislike changes in Walker carcinoma 256-bearing rats, not accompanied with hypercalcemia or parathyroid hormone related protein production, Jpn. J. Cancer Res., 86, 470-476 (1995).

15) H. Shimano, N. Y ahagi, M. A memiya Kudo, A.H. Ha sty, J. Osuga, Y. Tamura, F. Shionoiri, Y. lizuka, K. Ohashi, K. Harada, T. Gotoda, S. Ishibashi, N. Y ama da, Sterol regulatory element-binding protein-1 as a key transcription factor for nutritional induction of lipogenic enzyme genes, J. Biol. Chem., 274, 35832-35839 (1999).

16) J.P. Bonnefont, F. Djouadi, C. Prip-Buus, S. Gobin, A. Munnich, J. Bastin, Carnitine palmitoyltransferases 1 and 2 : biochemical, molecular and medical aspects, Mol. Aspects Med ., 25, 495-520 (2004).

17) E.H. Mischler, S.W. Parrell, P.M. Farrell, W.J. Raynor, R.J. Lemen, Correction of linoleic acid deficiency in cystic fibrosis, Pediatr. Res., 20, 36-41 (1986).

18) T. Yoshikawa, H. Shimano, N. Yahagi, T. Ide, M. Amemiya Kudo, T. Matsuzaka, M. Nakakuki, S. Tomita, H. Okazaki, Y. Tamura, Y. Iizuka, K. Ohashi, A. Taka hashi, H. Sone, J. O suga Ji, T. Gotoda, S. Ishibashi, N. Yamada, Polyunsaturated fatty acids suppress sterol regulatory element-binding protein $1 \mathrm{c}$ promoter activity by inhibition of liver $X$ receptor ( $L X R)$ binding to $L X R$ response elements, J. Biol. Chem., 277, 1705-1711 (2002).

19) S.D. Clarke, P. Thuillier, R.A. Baillie, X. Sha, Peroxisome proliferator-activated receptors: a family of lipidactivated transcription factors, Am. J. Clin. Nutr., 70, 566-571 (1999).

20) S. Kersten, Effects of fatty acids on gene expression : role of peroxisome proliferator-activated receptor alpha, liver $X$ receptor alpha and sterol regulatory elementbinding protein-1c, Proc. Nutr. Soc., 61, 371-374 (2002).

21) G. Liang, J. Y ang, J.D. Horton, R.E. Hammer, J.L. GoIdstein, M.S. Brown, Diminished hepatic response to fasting/refeeding and liver $X$ receptor agonists in mice with selective deficiency of sterol regulatory elementbinding protein-1c, J. Biol. Chem., 277, 9520-9528 (2002).

22) A.L. Buchman, M. Dubin, D. Jenden, A. Moukarzel, M.H. Roch, K. Rice, J. Gornbein, M.E. A ment, C.D. Eckhert, Lecithin increases plasma free choline and de creases hepatic steatosis in long-term total parenteral nutrition patients, Gastroenterology, 102, 1363-1370 (1992). 
23) C.E. Buchmiller, R.L. Kleiman-Wexler, K.S. Ephgrave, B. Booth, C.E. Hensley $2^{\text {nd }}$, Liver dysfunction and energy source: results of a randomized clinical trial, $J$. Parenter. Enteral Nutr., 17, 301-306 (1993).

24) J. Ha, J.K. Lee, K.S. Kim, L.A. Witters, K.H. Kim, Cloning of human acetyl-CoA carboxylase-beta and its unique features, Proc. Natl. Acad. Sci. U.S.A., 93, 11466-11470 (1996).

25) N. Berriot-V aroqueaux, L.P. A ggerbeck, M. SamsonBouma, J.R. Wetterau, The role of the microsomal triglygeride transfer protein in abetalipoproteinemia, Annu. Rev. Nutr., 20, 663-697 (2000). 